\title{
Qualidade de sementes de feijão-caupi tratadas com produtos químicos e armazenadas em condições controladas e não controladas de temperatura e umidade
}

\section{Quality of cowpea seeds treated with chemicals and stored in controlled and uncontrolled temperature and humidity conditions}

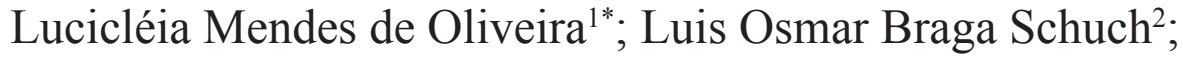 \\ Riselane de Lucena Alcântara Bruno ${ }^{3}$; Silmar Teichert Peske ${ }^{2}$
}

\section{Resumo}

O feijão-caupi é uma Fabaceae de origem africana cultivada na região norte e nordeste do Brasil, onde se destaca como principal fonte proteica para a população. Para o estabelecimento da cultura, as sementes são tratadas para controlar e prevenir ataques de pragas e doenças, também é possível agregar nutrientes às sementes os quais estarão disponíveis para a planta em desenvolvimento. O objetivo da pesquisa foi avaliar o desempenho de sementes de feijão-caupi tratadas com produtos químicos e armazenadas em condições controladas e não controladas de temperatura e umidade. As sementes foram submetidas aos seguintes tratamentos: testemunha (sem tratamento); micronutriente COMOL 118; inseticida tiametoxam; fipronil+piraclostrobina+tiofanato metílico e imidacloprido+tiodicarbe sendo posteriormente armazenadas em ambiente natural e câmara fria. A avaliação da qualidade fisiológica foi realizada em sementes recém colhidas e armazenadas utilizando testes de germinação e vigor. Dos produtos utilizados, o imidacloprid + thiodicarb e o fipronil + piraclostrobina + tiofanato metílico proporcionam efeito estimulante sobre o desempenho das sementes; sementes tratadas com tiametoxam foram menos afetadas pelo armazenamento em relação às não tratadas; o tratamento com micronutrientes apresenta comportamento similar às sementes não tratadas e o armazenamento em ambiente controlado preserva a qualidade fisiológica das sementes.

Palavras-chave: Vigna unguiculata, tratamento de sementes, qualidade fisiológica

\begin{abstract}
The cowpea is a Fabaceae originated in Africa cultivated in the northern and northeastern of Brazil, where stands out as the main source of protein for the population. For the establishment of culture, seeds are treated to control and prevent pest attacks and diseases, can also attach nutrients to the seeds which will be available for plant development. The objective of the research was to evaluate the performance of cowpea seeds treated with chemical products and stored in controlled and uncontrolled temperature and humidity conditions. The following seeds treatments were applied: control (no treatment); micronutrient Comol 118, insecticide thiamethoxam, fipronil and pyraclostrobin+thiophanate-methyl and imidacloprid+thiodicarb were then stored in a cold environment and natural. The assessment of physiological seed quality was made initially and every 45 days through the germination and vigor.
\end{abstract}

\footnotetext{
Bióloga, Dr. em Ciência \& Tecnologia de Sementes, Bolsista PNPD, Universidade Federal do Tocantins, UFT, Campus de Gurupi, Gurupi, TO. E-mail: lucicleia@biologa.bio.br

2 Eng ${ }^{\text {os }}$ Agros , Profs. Drs. do Programa de Pós-graduação em Ciência e Tecnologia de Sementes, Universidade Federal de Pelotas, UFPel, Pelotas, RS. E-mail: lobs@ufpel.edu.br; peske@ufpel.edu.br

3 Eng ${ }^{\mathrm{a}}$ Agra, Prof $^{\mathrm{a}} \mathrm{Dr}^{\mathrm{a}}$ do Programa de Pós Graduação em Agronomia PPGA/DFCA/CCA, Universidade Federal da Paraíba, UFPB, Areia, PB. E-mail: riselane@pq.cnpq.br

* Autor para correspondência
} 
Among all products used, the imidacloprid + thiodicarb and fipronil + pyraclostrobin + thiophanate methyl provides stimulating effect on seed performance; seeds treated with thiamethoxam were less affected by storage than the untreated seeds; seeds treated with micronutrients exhibits similar behavior to untreated seeds and storage in a controlled environment better preserves the seed physiological quality.

Key words: Vigna unguiculata, seed treatment, physiological quality

\section{Introdução}

O feijão-caupi (Vigna unguiculata (L.) Walp.) é uma planta herbácea, autógama, de origem africana. Dentre as espécies cultivadas é uma das mais adaptadas, versátil e nutritiva, servindo como componente essencial dos sistemas de produção nas regiões secas dos trópicos, cobrindo parte da Ásia, Estados Unidos, Oriente Médio e Américas Central e do Sul (SINGH et al., 2002).

No Brasil a produtividade média do feijãocaupi ainda é baixa devido ao uso de cultivares tradicionais, pouco uso de insumos agrícolas, ausência de adubação ou forma inadequada de nutrição. Contudo, em algumas regiões do país a produção tem melhorado devido ao uso de tecnologias, cultivares mais produtivas, resistente a pragas e doenças (FREIRE FILHO et al., 2005).

O tratamento de sementes é uma prática cada vez mais utilizada para diferentes culturas, pois através dessa tecnologia é possível agregar produtos as sementes para protegê-las contra pragas presentes na própria semente e no solo (VANIN et al., 2011). À medida que aumenta o valor da semente e a importância de proteger ou melhorar seu desempenho surge no mercado novos produtos, alguns proporcionam alterações morfológicas e fisiológicas nas plantas (ALMEIDA et al., 2011), outros tem finalidade de nutrição como os micronutrientes. Porém, o uso desses produtos para posterior armazenamento das sementes nem sempre traz benefícios à qualidade fisiológica e muitas vezes podem se tornar tóxicos dependendo do tipo, dose e período de tempo que ficam estocadas (AVELAR et al., 2011).
Alguns produtos químicos utilizados no tratamento de sementes proporcionam alterações fisiológicas nas plantas, com tendência de estabelecer crescimento vigoroso e com melhor aproveitamento do seu potencial produtivo, tal efeito é conhecido como fitotônico (CASTRO et al., 2008), constatado em dois potentes inseticidas, tiametoxam e o aldicarbe. Também há relatos que o fipronil incrementa massa seca de plantas e crescimento radicular conferindo maior tolerância das plantas as condições adversas (SILVA et al., 2009).

Em sementes de feijão não há relatos sobre o efeito desses produtos sobre o potencial produtivo da planta, mas Pereira (2010) constatou que o tiametoxan proporciona aumento da área foliar, massa seca da parte aérea e aumento da atividade da nitrato redutase em folhas, e quando realizada a pulverização com esse produto verifica-se aumentos na atividade da nitrato redutase e da fenilalanina amônio liase.

As culturas agrícolas destinadas à produção de alimentos estão sujeitas ao ataque de pragas e doenças, contudo, para preservar a qualidade das sementes estas podem ser tratadas e armazenadas. Nesse sentido, pesquisadores (DAN et al., 2011; DAN et al., 2012) vêm realizando estudos com tratamento de sementes previamente à semeadura para protegê-las, e analisar o efeito dos produtos sobre a qualidade fisiológica das sementes estocadas, bem como as suas respectivas plântulas. Diante do exposto, a pesquisa objetivou avaliar o desempenho de sementes de feijão-caupi tratadas com produtos químicos e armazenadas em condições controladas e não controladas de temperatura e umidade. 


\section{Material e Métodos}

O experimento foi conduzido no Laboratório de Análise de Sementes da Universidade Federal da Paraíba/UFPB, no Campus de Areia, Paraíba, utilizando sementes de Vigna unguiculata, cultivar BRS Cauamé, safra 2011/2012. Foram realizados os tratamentos de sementes: Testemunha (sem tratamento); Micronutriente COMOL 118 (composto por cobalto $1 \%$ e Molibdênio $8 \%$, sendo utilizado $300 \mathrm{~mL} 100 \mathrm{~kg}^{-1}$ de sementes); inseticida tiametoxam (Cruiser $350 \mathrm{FS} \AA-300 \mathrm{~mL}$ $100 \mathrm{~kg}^{-1}$ de sementes); Inseticida e fungicidas: fipronil e piraclostrobina+tiofanato metílico (Standak ${ }^{\circledR}$ top - $200 \mathrm{~mL} 100 \mathrm{~kg}^{-1}$ de sementes) e Imidacloprido+tiodicarbe (Cropstar ${ }^{\circledR}$ - 300 $\mathrm{mL} 100 \mathrm{~kg}^{-1}$ de sementes). Para que a calda total (produto + água) atingisse o volume máximo de 600 $\mathrm{mL} 100 \mathrm{~kg}^{-1}$ de sementes foi adicionado água. $\mathrm{O}$ recobrimento das sementes foi feito manualmente, o qual consistiu em colocar $1,8 \mathrm{~mL}$ de calda no fundo de saco plástico transparente, onde foram adicionados $300 \mathrm{~g}$ de sementes, procedendo em seguida a agitação do saco a fim de obter uma distribuição uniforme. Essa técnica foi realizada sucessivas vezes até se obter $3 \mathrm{~kg}$ de sementes para cada tratamento.

Após tratadas, parte das sementes foi submetida à avaliação da qualidade fisiológica inicial e a outra parte dividida em amostras de $300 \mathrm{~g}$, acondicionadas em embalagem plástica e armazenadas em ambiente natural cuja temperatura média foi de $27{ }^{\circ} \mathrm{C}$ e umidade relativa (UR) de $63 \%$ e em câmara fria (16 ${ }^{\circ} \mathrm{C}$ e $60 \%$ UR) para serem avaliadas aos 45; 90; 135 e 180 dias, sendo que as mesmas ficaram armazenadas de março a agosto de 2012. Foi determinado o teor de água das sementes inicialmente e a cada período de armazenamento e para avaliar a qualidade fisiológica realizou-se teste de germinação e vigor como descrito a seguir:

O teor de água foi determinado pelo método da estufa a $105 \pm 3{ }^{\circ} \mathrm{C}$ durante 24 horas, efetuando-se quatro repetições de $10 \mathrm{~g}$ por tratamento conforme descrito por Brasil (2009); O Teste de germinação foi realizado utilizando-se 200 sementes por tratamento, semeadas em papel toalha (germitest ${ }^{\circledR}$ ) umedecido com água destilada equivalente a três vezes o peso do papel seco, sendo posteriormente mantidas em germinador regulado a $25{ }^{\circ} \mathrm{C}$. As contagens foram realizadas aos cinco e oito dias após semeadura (BRASIL, 2009); Primeira contagem de germinação - conduzida juntamente com o teste de germinação sendo a contagem realizada aos cinco dias após semeadura; Envelhecimento acelerado amostras de 200 sementes foram distribuídas sobre tela de aço suspensa no interior de caixas plásticas tipo "gerbox", contendo $40 \mathrm{~mL}$ de água destilada, sendo mantidas em incubadora tipo BOD a 42 ${ }^{\circ} \mathrm{C}$, durante 48 horas (DUTRA; TEÓFILO, 2007). Decorrido o período de exposição, as sementes foram colocadas para germinar conforme descrito na metodologia para o teste de germinação, sendo a contagem realizada aos cinco dias após semeadura; Comprimento de plântulas - foram empregadas 20 sementes por repetição sendo semeadas no papel toalha (germitest ${ }^{\circledR}$ ) préumedecido, em seguida mantidas em germinador regulado a $25^{\circ} \mathrm{C}$ (NAKAGAWA, 1999). Aos cinco dias após a semeadura, as plântulas normais foram medidas desde a ponta da raiz até a inserção dos cotilédones, sendo os resultados expressos em $\mathrm{cm}$; Teste de emergência foram utilizadas 100 sementes distribuídas em quatro repetições de 25 sementes, semeadas em areia lavada utilizando a profundidade de semeadura de $3 \mathrm{~cm}$ e mantidas em casa de vegetação. A contagem final foi realizada aos 12 dias após a semeadura, sendo os resultados expressos em porcentagem; $\boldsymbol{O}$ índice de velocidade de emergência foi realizado juntamente com o teste de emergência com contagem diária das plântulas emersas e calculado através da fórmula proposta por Maguire (1962).

O delineamento experimental utilizado foi inteiramente casualizado em esquema fatorial $2 \mathrm{x}$ 5 x 5 (ambientes de armazenamento, tratamentos de sementes e períodos de armazenamento) com 
quatro repetições. Os dados foram submetidos à análise de variância, sendo os efeitos dos tratamentos avaliados pelo teste F. Para a avaliação do fator período de armazenamento foi realizada a análise de regressão polinomial. Anteriormente ao armazenamento avaliaram-se os efeitos dos tratamentos, utilizando-se o teste de Duncan, ao nível de $5 \%$ de probabilidade.

\section{Resultados e Discussão}

De acordo com a análise da variância, observase interação significativa para os tratamentos e períodos de armazenamento para todas as variáveis analisadas (Tabela 1).

Tabela 1. Resumo da análise de variância da determinação do teor de água e testes de qualidade fisiológica de sementes de feijão-caupi tratadas com inseticidas, fungicidas e micronutrientes, armazenadas durante 180 dias, em condições controladas e não controladas de temperatura e umidade.

\begin{tabular}{lllllllll}
\hline & & \multicolumn{7}{c}{ Quadrado Médio } \\
\cline { 3 - 4 } Fonte de variação & GL & TA & G & PCG & EA & CP & EM & IVE \\
\hline Tratamentos (T) & 4 & $1,1426^{* *}$ & $82,12^{* *}$ & $294,79^{* *}$ & $93,35^{* *}$ & $20,541^{* *}$ & $1430,7^{* *}$ & $6,337^{* *}$ \\
Período (P) & 4 & $0,8277^{* *}$ & $564,97^{* *}$ & $2482^{* *}$ & $1424,2^{* *}$ & $41,353^{* *}$ & $4984,8^{* *}$ & $60,179^{* *}$ \\
Ambiente (A) & 1 & $1,3778^{* *}$ & $167,45^{* *}$ & $1008^{* *}$ & $744,98^{* *}$ & $0,7345^{\text {ns }}$ & $8359,2^{* *}$ & $18,313^{* *}$ \\
T X P & 16 & $0,1102^{*}$ & $25,033^{* *}$ & $85,452^{* *}$ & $161,22^{* *}$ & $3,92^{\text {ns }}$ & $378,72^{* *}$ & $2,0571^{* *}$ \\
A X P & 4 & $0,3114^{* *}$ & $97,145^{* *}$ & $213,54^{* *}$ & $142,22^{* *}$ & $3,558^{\text {ns }}$ & $1150,4^{* *}$ & $5,6864^{* *}$ \\
T X A & 4 & $0,0771^{\text {ns }}$ & $31,595^{* *}$ & $141,24^{* *}$ & $116,21^{* *}$ & $4,9242^{\text {ns }}$ & $637,6^{* *}$ & $2,3327^{* *}$ \\
T X A X P & 16 & $0,119^{* *}$ & $25,514^{\text {ns }}$ & $84,952^{* *}$ & $67,958^{* *}$ & $3,6592^{\text {ns }}$ & $165,66^{* *}$ & $0,7601^{* *}$ \\
Repetição & 3 & $0,0703^{\text {ns }}$ & $6,5783^{\text {ns }}$ & $14,458^{\text {ns }}$ & $3,8733^{\text {ns }}$ & $12,741^{\text {ns }}$ & $4,685^{\text {ns }}$ & $0,4718^{\text {ns }}$ \\
Resíduo & 147 & 0,067 & 11,378 & 19,173 & 14,887 & 2,9191 & 15,039 & 0,2606 \\
\hline CV (\%) & & 2,29 & 3,91 & 5,54 & 5,17 & 9,61 & 4,58 & 10,91 \\
\hline
\end{tabular}

TA - Teor de água (\%); G - Germinação (\%); PCG - Primeira contagem de germinação (\%); EA - Envelhecimento acelerado (\%); $\mathrm{CP}$ - Comprimento de plântulas (cm); EM - Emergência (\%); IVE - Índice de velocidade de emergência. CV - Coeficiente de variação. ${ }^{\mathrm{ns}}, * *$, * respectivamente, não significativo e significativo a $1 \%$ e $5 \%$ de probabilidade pelo teste $\mathrm{F}$.

Fonte: Elaboração dos autores.

A determinação do teor de água das sementes mostrou que houve pequeno acréscimo na umidade inicial das mesmas de $11,2 \%$ durante o período de armazenamento para 0,3 pontos percentuais. (Dados não apresentados). Este aumento pode ser explicado pelo equilíbrio higroscópico das sementes que é de $12 \%$ para sementes armazenadas a $60 \%$ de umidade relativa e $25{ }^{\circ} \mathrm{C}$, condições essas similares às utilizadas nesse estudo.

As sementes tratadas com os diferentes produtos apresentaram pequenas diferenças com relação ao teor de água durante o armazenamento, sendo importante destacar que para obter melhor conservação da qualidade fisiológica das sementes ortodoxas é desejável que o teor de água das mesmas seja igual ou inferior a $12 \%$. Pois segundo Baudet e Villela (2012) há uma estreita relação entre o teor de água das sementes com o potencial de armazenamento, sendo que para cada diminuição de $1 \%$ no teor de água das sementes implica na duplicação do potencial de armazenamento. Por isso, é importante reduzir o teor de água das sementes para minimizar a atividade respiratória, reduzir o consumo das reservas e consequentemente conservá-las por mais tempo, principalmente, se mantidas em ambiente com controle de temperatura e umidade relativa do ar (MENEZES; VILLELA, 2009). 
Logo após o tratamento das sementes, germinação das sementes de feijão-caupi, o mesmo anteriormente ao armazenamento (Tabela 2), não aconteceu para MICRO que proporcionou verificou-se que os tratamentos FPTM, TIAM comportamento semelhante à testemunha (TEST). e $\mathrm{I}+\mathrm{T}$ condicionaram efeito estimulante sobre a

Tabela 2. Qualidade fisiológica de sementes recém colhidas de feijão-caupi tratadas com micronutrientes (MICRO), tiametoxam (TIAM), fipronil+piraclostrobina+tiofanato metílico (FPTM), imidacloprido+tiodicarbe (I+T) e uma testemunha (TEST) antes do armazenamento.

\begin{tabular}{ccccccc}
\hline TRAT & G & PCG & EA & CP & EM & IVE \\
\hline TEST & $88 \mathrm{~B}$ & $88 \mathrm{~A}$ & $82 \mathrm{~B}$ & $19,9 \mathrm{~A}$ & $98 \mathrm{~A}$ & $6,0 \mathrm{~B}$ \\
MICRO & $89 \mathrm{~B}$ & $85 \mathrm{~B}$ & $89 \mathrm{~A}$ & $19,5 \mathrm{~A}$ & $97 \mathrm{~A}$ & $6,3 \mathrm{~A}$ \\
TIAM & $90 \mathrm{~A}$ & $88 \mathrm{~A}$ & $73 \mathrm{C}$ & $18,0 \mathrm{~A}$ & $97 \mathrm{~A}$ & $6,4 \mathrm{~A}$ \\
FPTM & $94 \mathrm{~A}$ & $92 \mathrm{~A}$ & $90 \mathrm{~A}$ & $18,8 \mathrm{~A}$ & $95 \mathrm{~A}$ & $6,7 \mathrm{~A}$ \\
I+T & $95 \mathrm{~A}$ & $92 \mathrm{~A}$ & $84 \mathrm{~B}$ & $20,7 \mathrm{~A}$ & $97 \mathrm{~A}$ & $5,7 \mathrm{~B}$ \\
\hline CV $(\%)$ & 3,91 & 5,54 & 5,71 & 9,61 & 4,58 & 10,91 \\
\hline
\end{tabular}

G - Germinação (\%); PCG - Primeira contagem de germinação (\%); EA - Envelhecimento acelerado (\%); CP - Comprimento de plântulas (cm); EM - Emergência (\%); IVE - Índice de velocidade de emergência. Médias seguidas das mesmas letras maiúsculas na coluna não diferem entre si (Scott-Knott 5\%).

Fonte: Elaboração dos autores.

A germinação das sementes de feijão-caupi foi influenciada por todos os tratamentos utilizados antes e após o armazenamento. Tal fato não foi constatado por Dan et al. (2012) em experimento com sementes de girassol quando tratadas com tiametoxam ou fipronil, mas quando tratadas com imidacloprido+tiodicarbe foi verificada uma redução no potencial de germinação e no índice de velocidade de emergência devido ao efeito tóxico do produto sobre a qualidade fisiológica das mesmas.

$\mathrm{Na}$ Figura 1A verifica-se que sementes não tratadas (TEST) e tratadas com os produtos $\mathrm{I}+\mathrm{T}$ foram responsáveis por reduções de 10 e 9\%, respectivamente, na viabilidade das sementes e o tempo de armazenamento influenciou especialmente as sementes não tratadas. Em sementes de soja, Dan et al. (2011), observaram-se que a resposta germinativa foi semelhante à obtida pelas sementes de feijão-caupi para o tratamento tiametoxam, o qual também não foi influenciado pelo tempo de armazenamento. Por outro lado, o tratamento constituído por imidacloprido+tiodicarbe causou prejuízos à germinação.
No ambiente controlado (Figura 1B) observase que a germinação foi reduzida ao longo do tempo de estocagem da semente, com velocidade mais acentuada para aquelas tratadas com FPTM confirmando maior efeito desse produto de maneira negativa. As sementes não tratadas e tratadas com MICRO e TIAM apresentam comportamento similar de redução do potencial de germinação, enquanto aquelas contendo os produtos $\mathrm{I}+\mathrm{T}$ tendem a reduzir mais acentuadamente a qualidade com perdas de 2,6 pontos percentuais por mês. Mesmo assim, quando comparado com os outros produtos verifica-se que o tratamento $\mathrm{I}+\mathrm{T}$ é o que melhor preserva a qualidade das sementes até os 135 dias de armazenamento contendo, ainda, porcentagem de germinação de $84 \%$, demonstrando, em geral, resultado superior ao TEST.

Durante o armazenamento em ambiente natural (Figura 2A) observa-se que com o aumento do tempo ocorreu redução do vigor para todos os tratamentos, sendo que o FPTM proporciona redução até os 90 dias e depois se mantém praticamente inalterado até os 180 dias. 
Figura 1. Germinação de sementes de feijão-caupi armazenadas em ambiente natural (A) e controlado (B) durante 180 dias. Tratamentos: Testemunha (TEST); Micronutrientes (MICRO); Tiametoxam (TIAM); Fipronil+piraclostrob ina+tiofanato metílico (FPTM); Imidacloprido+tiodicarbe (I+T).
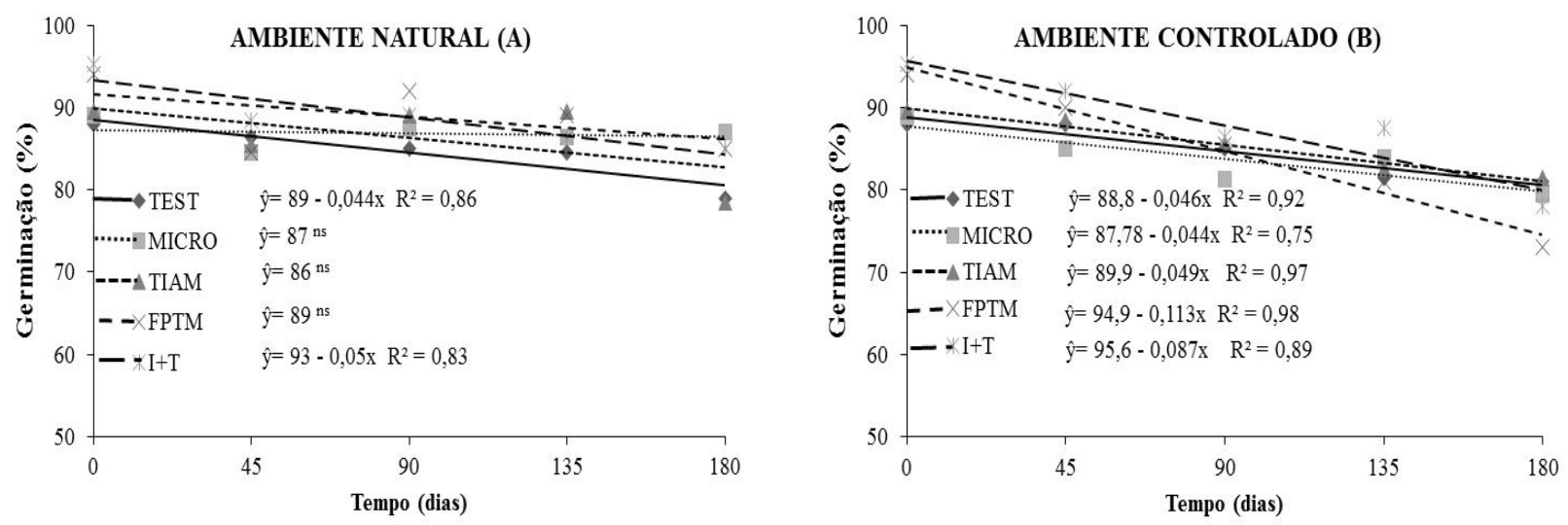

Fonte: Elaboração dos autores.

Figura 2. Primeira contagem de germinação das sementes de feijão-caupi armazenadas em ambiente natural (A) e controlado (B) durante 180 dias. Tratamentos: Testemunha (TEST); Micronutrientes (MICRO); Tiametoxam (TIAM); Fipronil+piraclostrobina+tiofanato metílico (FPTM); Imidacloprido+tiodicarbe (I+T).
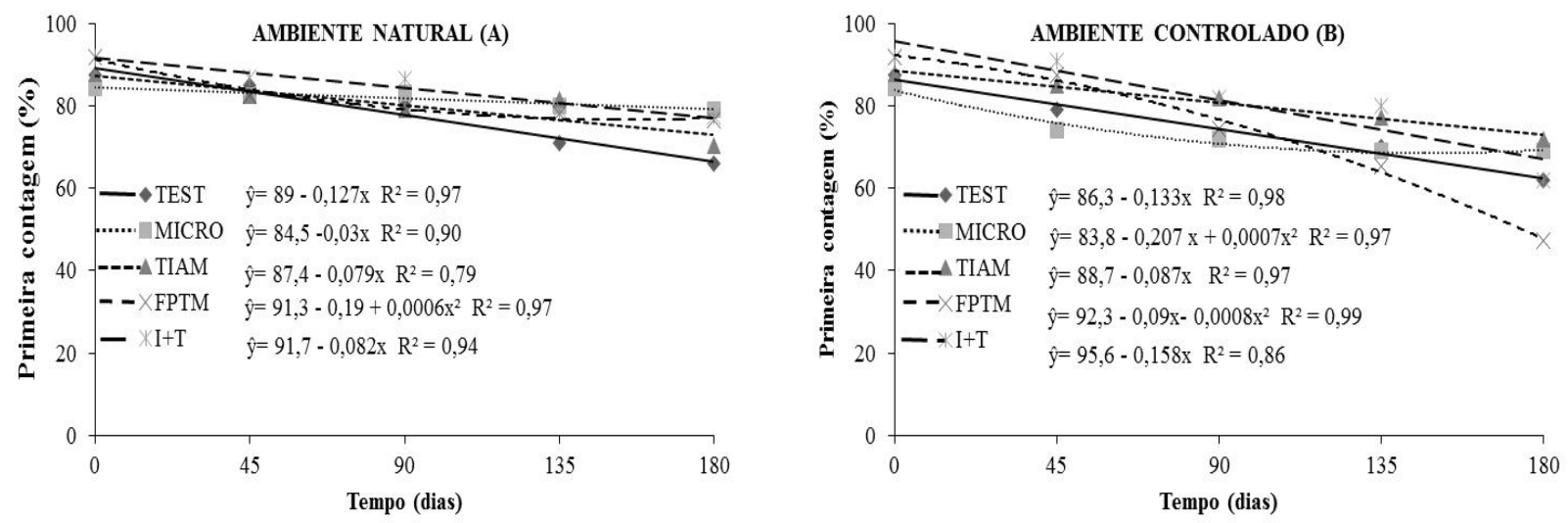

Fonte: Elaboração dos autores.

No ambiente controlado (Figura 2B) constata-se redução do vigor das sementes com o prolongamento do armazenamento para todos os tratamentos, sendo mais expressiva no tratamento $\mathrm{I}+\mathrm{T}$ com $28 \%$ e menos acentuada no TIAM com $15 \%$. O tratamento MICRO causou redução do vigor até os 135 dias, já FPTM se destaca por afetar mais intensamente a qualidade das sementes após 90 dias indicando que algum desses ingredientes ativos possa causar efeito fitotóxico sobre as sementes, manifestando provável efeito após armazenadas. Até os 45 dias de armazenamento, os tratamentos mantiveram o vigor das sementes acima de $80 \%$, exceção feita para TEST e MICRO. Dessa forma, os ingredientes ativos protetores (inseticidas e fungicidas) beneficiaram a qualidade fisiológica das sementes neste período. A partir dos 90 dias de armazenamento o TIAM e o $\mathrm{I}+\mathrm{T}$ proporcionaram um maior vigor nas sementes em relação à testemunha. 
O teste de vigor baseia-se no princípio de que sementes que originarem maior porcentagem de plântulas normais na primeira contagem de germinação são as mais vigorosas, indiretamente avaliando a velocidade de germinação (BRASIL, 2009). Portanto, à medida que reduz a agilidade de resposta das sementes para iniciar a germinação infere-se que esta apresenta menor possibilidade de expressar seu potencial fisiológico, de originar plântulas normais, fortes e sobreviverem às condições desfavoráveis de campo.

Ao analisar o envelhecimento acelerado (Tabela 2), constata-se que os maiores valores de porcentagem de germinação foram obtidos pelas sementes submetidas ao tratamento FPTM e MICRO, enquanto o tratamento TIAM foi o responsável pelas maiores reduções da qualidade fisiológica das sementes. Diferindo dos resultados obtidos por Almeida et al. (2009), pois ao tratar sementes de cenoura com tiametoxam constataram que o produto gerava incrementos variando de 2 a 11 pontos percentuais.

Durante o armazenamento em ambiente natural (Figura 3A) pode-se notar que sementes não tratadas e tratadas com FPTM mostraram redução do vigor ao longo do período, especialmente para as não tratadas. As sementes submetidas ao tratamento com MICRO tiveram uma redução de $23 \%$ até os 120 dias e, as com o TIAM mostraram incrementos na qualidade de $5 \%$ até os 90 dias de armazenamento, decrescendo a partir daí; enquanto as sementes submetidas ao I+T não foram afetadas pelo armazenamento. Durante o armazenamento constata-se que o tiametoxam promoveu efeito benéfico sobre o desempenho das sementes, já que elevou a capacidade das mesmas germinarem após terem sofrido um estresse de resistência de alta temperatura e umidade relativa por intermédio do teste de envelhecimento acelerado.

Figura 3. Envelhecimento acelerado de sementes de feijão-caupi armazenadas em ambiente natural (A) e controlado (B) durante 180 dias. Tratamentos: Testemunha (TEST); Micronutrientes (MICRO); Tiametoxam (TIAM); Fipronil+ piraclostrobina+tiofanato metílico (FPTM); Imidacloprido+tiodicarbe (I+T).
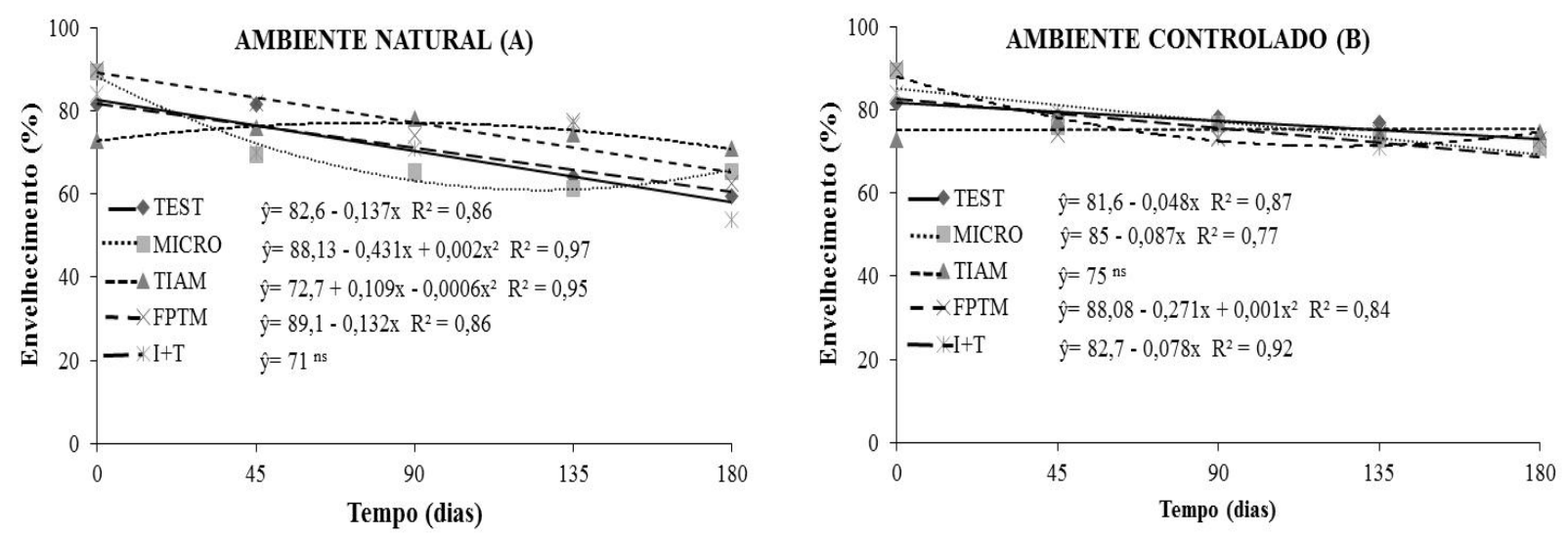

Fonte: Elaboração dos autores.

Como pode ser observado, o tiametoxam utilizado no tratamento das sementes de feijão proporcionou melhor expressão das sementes com possível efeito envigorante no decorrer de três meses de armazenamento. Tais resultados são corroborados por Almeida et al. (2009) ao verificar efeito desse produto como bioativador no desempenho fisiológico das sementes de cenoura. 
Estudos com sementes de soja também evidenciaram que sementes não tratadas e tratadas com micronutrientes influenciaram no seu desempenho após o armazenamento, fato detectado pelo teste de envelhecimento acelerado (AVELAR et al., 2011)

A variação de comportamento no ambiente controlado (Figura 3B) foi menos acentuada que no natural (Figura 3A), como esperado devido às condições de baixa temperatura e umidade relativa do ar. Notou-se que sementes não tratadas (TEST) e tratadas com MICRO e $\mathrm{I}+\mathrm{T}$ tiveram reduções lineares semelhantes. $\mathrm{O}$ tratamento FPTM acarretou redução de $16 \%$ até os 90 dias, estabilizando posteriormente, enquanto o TIAM não proporcionou efeito com o tempo de armazenamento.

É natural que as sementes percam vigor com o aumento do tempo de armazenamento, sendo que o tratamento das mesmas com produtos químicos pode acelerar ou retardar essa redução, dependendo do produto utilizado, da espécie e das condições de armazenamento. No entanto, as melhores condições para preservar a qualidade da semente são aquelas de baixa umidade relativa do ar e temperatura, pelo fato de manterem a semente em baixa atividade metabólica (CARVALHO; NAKAGAWA, 2012).

Logo após o tratamento das sementes (Tabela 2) quando comparado com a testemunha observa-se que os produtos agiram de maneira semelhante não influenciando sobre o comprimento de plântulas. Contrariamente ao observado nesta pesquisa com feijão, em sementes de arroz tratadas com tiametoxam observou-se desempenho superior de comprimento de plântulas em relação as não tratadas (ALMEIDA et al., 2011). Já as sementes de soja tratadas com tiametoxam alcançaram níveis adequados de germinação e vigor independente do período de armazenamento, enquanto os produtos imidacloprido+tiodicarbe foram responsáveis por reduções de $0,18 \mathrm{~cm}$ no comprimento de plântulas (DAN et al., 2011).

Em outro experimento com soja foi observado aumento no comprimento de raiz e parte aérea, no qual as raízes apresentaram-se mais delgadas e longas caracterizando o efeito fitotônio influenciando positivamente na melhor absorção de nutrientes pela planta. Isso ocorreu quando estes parâmetros foram analisados logo após as sementes serem tratadas com os ingredientes químicos tiametoxam e imidacloprido (CASTRO et al., 2008). Tal efeito não foi verificado em feijão-caupi logo após o tratamento das sementes com tiametoxam, mas durante o armazenamento foi observado incremento no comprimento de plântulas.

Ao avaliar o vigor das sementes (teste de comprimento de plântulas) quando armazenadas em ambiente natural (Figura 4A) verifica-se que os tratamentos MICRO, FPTM e I+T proporcionaram redução no crescimento ao longo do armazenamento, enquanto os demais tratamentos não causaram efeito. Destes tratamentos o MICRO destaca-se por interferir negativamente no desenvolvimento das plântulas e o I+T por proporcionar desenvolvimento superior com valor inicial de 21,28 cm. Em soja, também foi observado que o tratamento com tiametoxam não provocou efeito durante o período de armazenamento, não interferindo no comprimento das plântulas (DAN et al., 2011).

No ambiente controlado (Figura 4B) também nota-se redução do vigor das sementes com o aumento dos períodos de avaliação, com exceção das sementes sob influência do tratamento $\mathrm{I}+\mathrm{T}$ que não sofreu efeito do armazenamento. Apesar de não ter ocorrido alteração acentuada no comprimento de plântulas durante o armazenamento, evidenciou-se redução do vigor nos testes de primeira contagem de germinação, envelhecimento acelerado, emergência e IVE. Portanto, é válido destacar que independente dos tratamentos agregados às sementes, estas perdem o vigor, pois o processo de deterioração natural é inevitável e irreversível. Segundo Zimmer (2012) os sinais da deterioração das sementes aparecem à medida que o armazenamento avança e se manifesta com redução no crescimento das plântulas, porcentagem de germinação, emergência, aumento no número de plântulas anormais, entre outros fatores, demonstrando redução do vigor. 
Figura 4. Comprimento de plântulas de feijão-caupi oriundas de sementes armazenadas em ambiente natural (A) e controlado (B) durante 180 dias. Tratamentos: Testemunha (TEST); Micronutrientes (MICRO); Tiametoxam (TIAM); Fipronil+piraclostrobina+tiofanato metílico (FPTM); Imidacloprido+tiodicarbe (I+T).
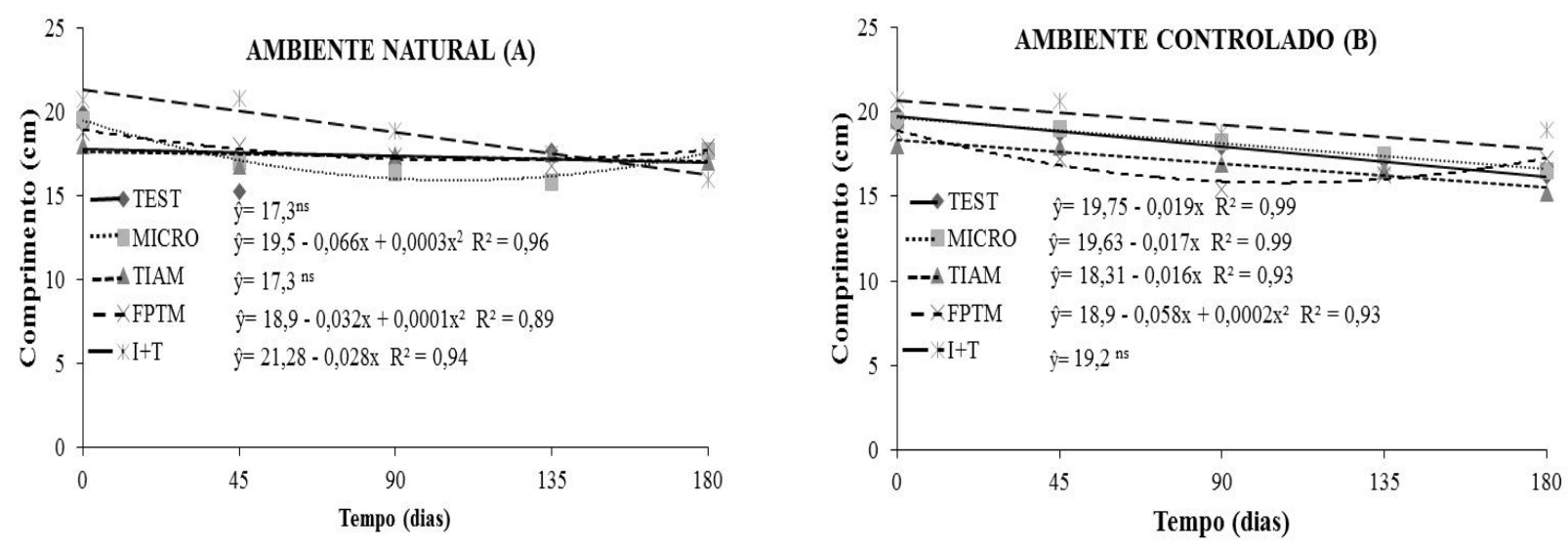

Fonte: Elaboração dos autores.

De acordo com os dados apresentados na Tabela 2 verifica-se que o teste de emergência não detectou nenhuma diferença sobre o desempenho das sementes logo após serem tratadas. No entanto, o teste evidencia que a qualidade foi afetada com o tempo de armazenamento. No ambiente natural (Figura 5A) verifica-se redução linear da porcentagem de emergência de plântulas, exceto para o FPTM que não sofreu influência do armazenamento. Enquanto os tratamentos MICRO, TIAM e TEST respectivamente, se destacam por serem os tratamentos que mais afetaram a qualidade fisiológica das sementes.

Figura 5. Emergência de plântulas de feijão-caupi oriundas de sementes armazenadas em ambiente natural (A) e controlado (B) durante 180 dias. Tratamentos: Testemunha (TEST); Micronutrientes (MICRO); Tiametoxam (TIAM); Fipronil+piraclostrobina+tiofanato metílico (FPTM); Imidacloprido+tiodicarbe (I+T).
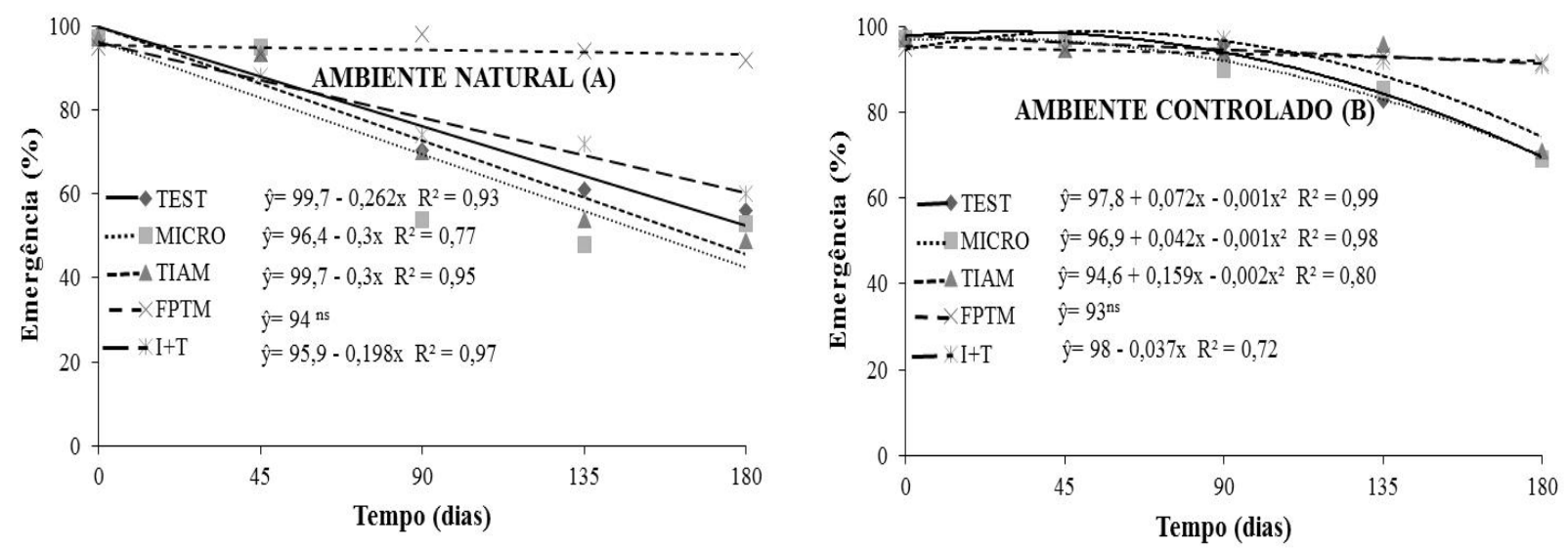

Fonte: Elaboração dos autores. 
No ambiente controlado (Figura 5B) o tratamento que melhor preservou a qualidade das sementes foi o $\mathrm{I}+\mathrm{T}$ já que o vigor das mesmas permaneceu praticamente inalterado durante todo o armazenamento. E sementes tratadas com FPTM não foram influenciadas pelo tempo de armazenamento independentemente do ambiente (Figura 5A e 5B) sem causar efeito deletério sobre a capacidade das plântulas emergirem, sobressaindo desta forma como sendo o tratamento que melhor preservou o desempenho das sementes. De maneira geral, o ambiente natural foi o que menos preservou o vigor.

O teste de emergência apresenta sua importância na avaliação da qualidade fisiológica de sementes tratadas, pois o mesmo possibilita a lixiviação dos produtos revestidos nas sementes, o que já não acontece utilizando o papel como substrato no qual o produto fica ao redor da semente, além disso, pode causar fitotoxidez. Comparando as médias na Tabela 2 dos diferentes tratamentos pelos quais as sementes foram submetidas, fica bem claro o efeito do papel como substrato de germinação em relação a areia, a qual foi utilizada no teste de emergência. Além do mais, o teste de emergência é um dos melhores para avaliar o desempenho das sementes tendo em vista que os resultados são correlacionados com as condições de campo.

No presente estudo observou-se que os produtos FPTM e I+T influenciaram sobre a qualidade das sementes até os 45 dias, de tal forma que os resultados apresentados pelos testes de vigor (primeira contagem, envelhecimento acelerado e comprimento de plântulas) no ambiente natural foram superior à testemunha. Diferentemente do observado nesse estudo, o imidacloprido+tiodicarbe bem como outros inseticidas utilizados no tratamento de sementes de sorgo, avaliados até os 30 dias de armazenamento sob condições naturais, não afetaram o vigor das mesmas e apresentaram resultados de emergência semelhante às sementes não tratadas (VANIN et al., 2011). Em girassol, os produtos imidacloprido+tiodicarbe também não prejudicaram a emergência de plântulas durante o período de avaliação de quatro meses (BUENO et al., 2010).

Utilizando diferentes testes para avaliar a qualidade fisiológica das sementes de feijão-caupi observou-se que ao final do armazenamento houve declínio no vigor para todos os tratamentos e independentemente do ambiente, sendo o declínio de qualidade mais expressivo para a emergência de plântulas e o IVE (Figura 5A e 6A) de forma mais intensa com a evolução do armazenamento em ambiente natural.

Para o índice de velocidade de emergência (IVE) constata-se que antes do armazenamento (Tabela 2), apenas o tratamento FPTM difere de I+T e mostrase estatisticamente igual à testemunha. Resultados similares foram observados por Grisi et al. (2009) em girassol logo após o tratamento das sementes com tiametoxam e diferentes quando tratadas com fipron il+piraclostrobina+tiofanato metílico. Fato também verificado em soja até os sete dias de armazenamento para esses produtos citados anteriormente, enquanto que o imidacloprido+tiodicarbe provocou redução do IVE (DAN et al., 2011).

Para o ambiente natural (Figura 6A) pode-se observar que o IVE reduziu significativamente com o prolongamento do armazenamento, sendo as reduções mais intensas de 2,4 e 2,6 para os tratamentos TIAM e MICRO, respectivamente. O índice de velocidade de emergência da testemunha inicialmente reduziu lentamente, mas a partir dos 90 dias passa a reduzir intensamente. Os tratamentos FPTM e I+T foram responsáveis pelas menores reduções de qualidade, quando comparados com os demais tratamentos. Respostas do tratamento de sementes reduzindo o vigor também foram observadas em sementes de girassol, segundo Bueno et al. (2010) esse fato ocorreu independente do inseticida utilizado no período de quatro meses de armazenamento, além do mais, aos 30 dias o tiametoxam destacou-se por ser o produto que mais afetou esse parâmetro de qualidade. 
No ambiente controlado (Figura 6B) também ocorreu redução do vigor só que de uma maneira menos acentuada que no ambiente natural. É possível observar que em torno de 110 dias de armazenamento todos os tratamentos apresentaram comportamento semelhante. Os tratamentos TEST,
MICRO e $\mathrm{I}+\mathrm{T}$ reduziram intensamente, de forma linear, o índice de velocidade de emergência ao longo de todo o período, enquanto o TIAM e FPTM apenas 1,6 e 1,7 pontos até os 90 dias, sendo que a partir desse momento o comportamento estabilizou.

Figura 6. Índice de velocidade de emergência (IVE) de plântulas de feijão-caupi oriundas de sementes armazenadas em ambiente natural (A) e controlado (B) durante 180 dias. Tratamentos: Testemunha (TEST); Micronutrientes (MICRO); Tiametoxam (TIAM); Fipronil+piraclostrobina+tiofanato metílico (FPTM); Imidacloprido+tiodicarbe $(\mathrm{I}+\mathrm{T})$.
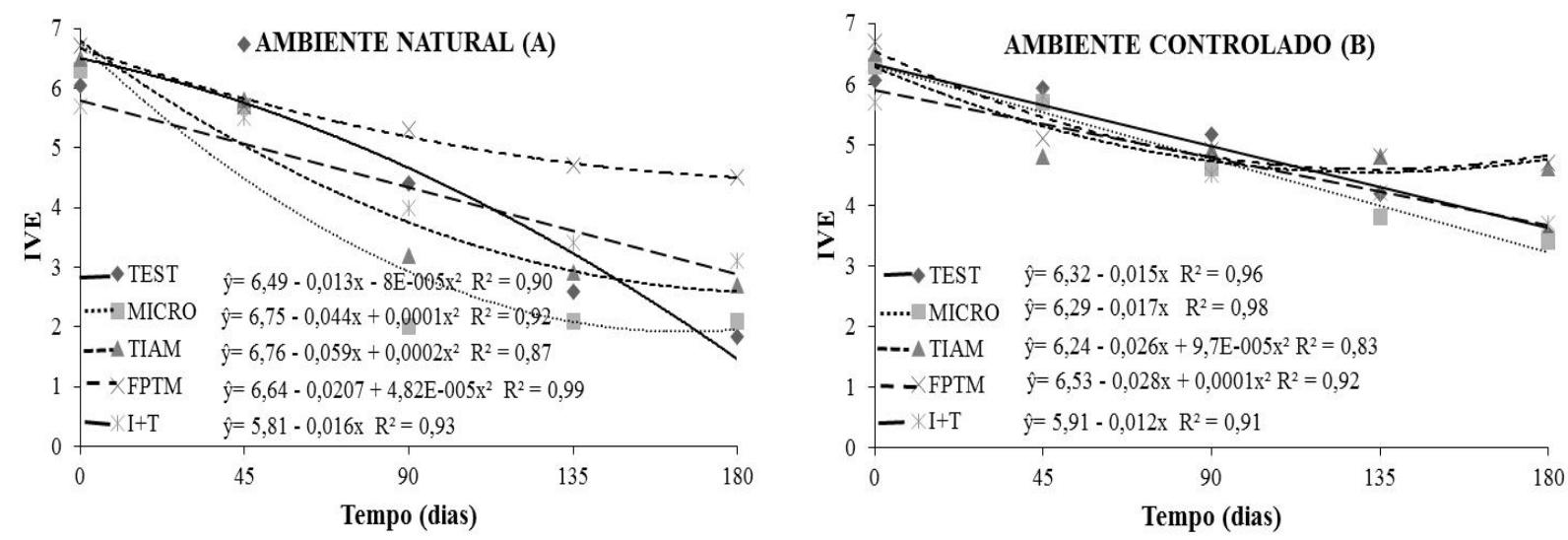

Fonte: Elaboração dos autores.

No ambiente controlado (Figura 6B) ocorreu menor alteração do vigor das sementes tendo em vista que tais condições preservaram melhor as características fisiológicas das sementes, uma vez que não houve oscilação do teor de água, mantendo baixa a respiração e o metabolismo, consequentemente reduzindo a intensidade de deterioração, proporcionando a conservação das sementes por mais tempo.

Em sementes de girassol os produtos imidacloprido+tiodicarbe apresentaram efeito negativo sobre o IVE retardando o arranque inicial das plântulas e reduzindo a porcentagem delas emergidas aos 30 dias de armazenamento (DAN et al., 2012), comportamento também observado em feijão-caupi neste estudo até 45 dias em ambiente natural (Figura 6A) quando comparado com a testemunha (TEST). Aos 180 dias de armazenamento, porém, esse produto proporcionou IVE superior à testemunha nesse ambiente.

Apesar dos tratamentos influenciarem a qualidade fisiológica das sementes, em alguns momentos, mostraram qualidade superior naquelas não tratadas. Inclusive nos testes de primeira contagem de germinação (Figura 2) e envelhecimento acelerado (Figura 3), em diversos períodos de armazenamento isso pode ser observado. O tratamento com micronutrientes mostrou-se semelhante à testemunha, não beneficiando nem prejudicando seu comportamento, exceção feita apenas aos 90 e 135 dias de armazenamento nos testes de emergência e IVE no ambiente natural (Figuras 5 e 6 ).

Diferentemente do observado por outros autores (CASTRO et al., 2008; ALMEIDA et al., 2011), o inseticida tiametoxam não proporcionou 
incrementos na porcentagem de germinação e vigor das sementes de feijão-caupi logo após o tratamento das sementes, por outro lado, nesse estudo foi constatado efeito estimulante do tiametoxam apenas para os testes de primeira contagem de germinação e envelhecimento acelerado em ambiente natural a partir dos 90 dias.

O tiametoxam é considerado um potencializador do poder germinativo das sementes. No entanto, a resposta pode variar em função da espécie, cultivar, qualidade fisiológica inicial, dose do produto e tempo de armazenamento segundo relatos da literatura. Para algumas culturas, tal produto proporciona efeitos positivos alterando características fisiológicas e morfológicas, enquanto em outras se mostra indiferente, restando apenas a sua função de controle de pragas iniciais durante o estabelecimento de plantas no campo.

Os produtos (fipronil+piraclostrobina+tio fanato metílico) utilizados no tratamento das sementes também não prejudicaram a qualidade fisiológica das sementes, e assim como o (imidacloprido+tiodicarbe) beneficiou a viabilidade destas gerando incrementos sobre a germinação, e com o prolongamento do armazenamento apresentou resultados similares à testemunha ou superior. As sementes tratadas com micronutrientes também não tiveram efeitos prejudiciais logo após a aplicação dos produtos. Constatando-se que os ingredientes ativos protetores, mantiveram a qualidade fisiológica das sementes em níveis semelhantes às não tratadas, ou preservaram a qualidade ao longo do armazenamento, não se verificando efeitos prejudiciais desses produtos sobre a qualidade fisiológica.

\section{Conclusões}

Os produtos imidacloprido+tiodicarbe e fiproni 1+piraclostrobina+tiofanato metílico proporcionam efeito estimulante sobre o desempenho das sementes; sementes revestidas com tiametoxam são menos afetadas pelo armazenamento; o tratamento com micronutrientes apresenta comportamento similar às sementes não tratadas e o armazenamento em ambiente controlado preserva a qualidade fisiológica das sementes.

\section{Referências}

ALMEIDA, A. S.; DEUNER, C.; TILLMANN, M. A. A.; VILLELA, F. A. Bioativador no desempenho fisiológico de sementes de arroz. Revista Brasileira de Sementes, Londrina, v. 33, n. 3, p. 501-510, 2011.

ALMEIDA, A. S.; TILLMANN, M. A. A.; VILLELA, F. A.; PINHO, M. S. Bioativador no desempenho fisiológico de sementes de cenoura. Revista Brasileira de Sementes, Londrina, v. 31, n. 3, p. 87-95, 2009.

AVELAR, S. A. G.; BAUDET, L.; PESKE, S. T.; LUDWING, M. P.; RIGO, G. A.; CRIZEL, R. L.; OLIVEIRA, O. Armazenamento de sementes de soja tratadas com fungicida, inseticida e micronutriente e recobertas com polímeros líquido e em pó. Ciência Rural, Santa Maria, v. 41, n. 10, p. 1719-1725, 2011.

BAUDET, L.; VILLELA, F. A. Armazenamento de Semente. In: PESKE, S. T.; VILLELA, F. A.; MENEGHELLO, G. E. (Ed.). Sementes: fundamentos científicos e tecnológicos. 3. ed. Pelotas: UFPEL, 2012. cap. 7, p. 482-527.

BRASIL. Ministério da Agricultura, Pecuária e Abastecimento. Regras para Análise de Sementes. Secretaria de Defesa Agropecuária. Diário Oficial [da] União, Brasília: MAPA/ACS, 01 out. 2009, nº 188, Seção 1, p. 1399.

BUENO. A. F.; SALES, J. F.; BUENO, R. C. O. F.; COSTA, R. G.; VIEIRA, S. S. Efeito do tratamento de sementes com inseticidas no controle de pragas iniciais e na qualidade fisiológica das sementes em girassol. Arquivo Instituto Biológico, São Paulo, v. 77, n. 1, p. 4956, 2010.

CARVALHO, N. M.; NAKAGAWA, J. Sementes: ciência, tecnologia e produção. 5. ed. Jaboticabal: FUNEP, 2012. $590 \mathrm{p}$.

CASTRO, G. S. A.; BOGIANI, J. C.; SILVA, M. G.; GAZOLA, E.; ROSOLEM, C. A. Tratamento de sementes de soja com inseticidas e um bioestimulante. Pesquisa Agropecuária Brasileira, Brasília, v. 43, n. 10, p. 1311-1318, 2008.

DAN, H. A.; GOULART, M. M. P.; DAN, L. G. M.; SILVA, A. G.; BARROSO, A. L. L.; BRACCINI, A. L.; MENEZES, J. F. S. Desempenho de sementes de girassol tratadas com inseticidas sob diferentes períodos 
de armazenamento. Revista Trópica - Ciências Agrárias e Biológicas, Chapadinha, v. 6, n. 1, p. 30-37, 2012.

DAN, L. G. M.; DAN, H. A.; BRACCINI, A. L.; ALBRECHT, L. P.; RICCI, T. T.; PICCININ, G. G. Desempenho de sementes de soja tratadas com inseticidas e submetidas a diferentes períodos de armazenamento. Revista Brasileira de Ciências Agrárias, Recife, v. 6, n. 2, p. 215-222, 2011.

DUTRA, A. S.; TEÓFILO, E. M. Envelhecimento acelerado para avaliar o vigor de sementes de feijão caupi. Revista Brasileira de Sementes, Londrina, v. 29, n. 1, p. 193-197, 2007.

FREIRE FILHO, F. R.; RIBEIRO, V. Q.; ALCÂNTARA, J. P.; BELARMINO FILHO, J.; ROCHA, M. M. BRS Marataoã: nova cultivar de feijão-caupi com grão tipo sempre-verde. Revista Ceres, Viçosa, MG, v. 52, n. 303, p. 771-777, 2005.

GRISI, P. U.; SANTOS, C. M.; FERNANDES, J. J.; SÁ JÚNIOR, A. Qualidade das sementes de girassol tratadas com inseticidas e fungicidas. Bioscience Journal, Uberlândia, v. 25, n. 4, p. 28-36, 2009.

MAGUIRE, L. D. Speed of germination - aid in selection and evolution for seedling emergence and vigor. Crop Science, Madison, v. 2, n. 2, p. 176-177, 1962.

MENEZES, N. L.; VILLELA, F. A. O Potencial de armazenamento de cada semente. SEED News, Pelotas, v. 1, n. 4, p. 22-25, 2009.
NAKAGAWA, J. Testes de vigor baseado em desempenho de plântulas. In: KRZYZANOWSKI, F. C.; VIEIRA, R. D.; FRANCA NETO, J. B. (Ed.). Vigor de sementes: conceitos e testes. Londrina: ABRATES, 1999. cap. 2, p. 1-24.

PEREIRA, M. A. Tiametoxam em plantas de cana-deaçúcar, feijoeiro, soja, laranjeira e cafeeiro: parâmetros de desenvolvimento e aspectos bioquímicos. 2010. Tese (Doutorado em Ciência) - Escola superior de Agricultura Luiz de Queiroz. Universidade de São Paulo, Piracicaba.

SILVA, C. P. L.; FAGAN, E. B.; ALVES, V. A. B.; CAIXETA, D. F.; SILVA, R. B.; GONÇALVES, L. A.; BORGES, A. F.; MARTINS, K. V. Avaliação do efeito de inseticidas em sementes de milho em diferentes profundidades de semeadura. Revista da FZVA, Uruguaiana, v. 16, n. 1, p. 14-21, 2009.

SINGH, B. B.; EHLERS, J. D.; SHARMA, B.; FREIRE FILHO, F. R. Recent progress in cowpea breeding. In: FATOKUN, C. A.; TARAWALI, S. A.; SINGH, B. B.; KORMAWA, P. M.; TAMÒ, M. (Ed.). Challenges and opportunities for enhancing sustainable cowpea production. Ibadan: IITA, 2002. p. 22-40.

VANIN, A.; SILVA, A. G.; FERNANDES, C. P. C.; FERREIRA, W. S.; RATTES, J. F. Tratamento de sementes de sorgo com inseticidas. Revista Brasileira de Sementes, Londrina, v. 33, n. 2, p. 299-309, 2011.

ZIMMER, P. D. Fundamentos da qualidade da semente. In: PESKE, S. T.; VILLELA, F. A.; MENEGHELlO, G. E. (Ed.). Sementes: fundamentos científicos e tecnológicos. Pelotas: UFPEL, 2012. cap. 2, p. 106-160. 
